\title{
EDUPESQUISA: O RECONHECIMENTO DA HISTORICIDADE DAS PESQUISAS
}

\section{EDUPESQUISA: THE RECOGNITION OF RESEARCHES HISTORICITY}

\author{
HEINZLE, Marcia Regina Selpa \\ selpamarcia@gmail.com \\ FURB - Universidade Regional de Blumenau \\ THEIS, Maria Stela Busarello \\ mariastelat@gmail.com \\ Gerência Regional de Educação de Blumenau \\ TOMAZONI, Eliane Kormann \\ eliane.kormann@unifebe.edu.br \\ UNIFEBE - Centro Universitário de Brusque
}

\section{RESUMO}

Este trabalho tem como objetivo identificar as principais temáticas das investigações que emergiram no Grupo de Pesquisa EduPesquisa do Programa de PósGraduação em Educação, Mestrado em Educação da Universidade Regional de Blumenau. Essas investigações foram desenvolvidas em quatro linhas, a saber: a) Epistemologia e Processos Metodológicos; b) Historicidade Sócio Institucional da Educação; c) Políticas e Administração da Educação; e d) Educação, Estado e Sociedade. O presente estudo, de abordagem qualitativa, considerou as interlocuções metodológicas do Estado da Arte, em que foram analisadas 28 dissertações orientadas pelo pesquisador Lauro Carlos Wittmann do Programa de Pós-Graduação citado. As pesquisas analisadas caracterizam-se em seu papel crítico e fundante na construção do conhecimento e remetem a sua pertinência em virtude dos desafios da organização da sociedade e no próprio campo educacional.

Palavras-chave: Educação. EduPesquisa. Historicidade. Produção Científica.

\section{ABSTRACT}

This work aims to identify the main themes of researches that emerged in the Research Group of EduPesquisa of the Program of Graduate Studies in Education, Master in Education of the Regional University of Blumenau. These investigations were developed in four lines, namely: a) Epistemology and Methodological Processes; b) Socio-Institutional Historicity of Education; c) Education Policies and Administration; and d) Education, State and Society. The present study, with a qualitative approach, considered the methodological interlocutions of the State of the Art, in which 28 dissertations were studied, guided by the researcher Lauro Carlos Wittmann of the mentioned Graduate Studies Program. The researches analyzed are characterized in their critical and foundational role in the construction of knowledge and refer to their pertinence due to the challenges of the organization of the society and in the educational field itself.

Keywords: Education. EduPesquisa. Historicity. Scientific production. 


\section{Atos de Pesquisa em Educação - ISSN 1809-0354 \\ Blumenau, v. 12, n.2, p.601-621, mai./ago. 2017 \\ DOI: http://dx.doi.org/10.7867/1809-0354.2017v12n2p601-621}

\section{INTRODUÇÃO}

O Programa de Pós-Graduação Mestrado em Educação (PPGE) da Universidade Regional de Blumenau (FURB) completou 25 anos de existência no ano de 2016. Desde sua criação, em 1991, vem trabalhando de forma crítica no seu aperfeiçoamento, em direção à excelência acadêmica. Nesse percurso de relevância sócio histórica, diversas dimensões investigativas foram desenvolvidas por meio de suas Linhas e Grupos de Pesquisa, nas suas diferentes delimitações e verticalizações de temas, ampliando seu acervo científico. Nesse sentido, compreende-se que a pós-graduação exerce papel fundante no contexto educativo e social. Para Wittmann (2006, p.122):

A Pós-Graduação é uma prática social decisiva no processo da (des)alienação das pessoas. Ela pode ser um poderoso mecanismo de resistência, emasculando o poder instituinte das pessoas e instituições, como pode ser um poderoso instrumento de transcendência, impulsionando a construção do novo, viabilizando a concretização de utopias.

Visando a perspectiva de transcendência, vários atores sociais participaram do Programa. Entre o corpo docente ressalta-se, neste estudo, um dos protagonistas, Professor Doutor Lauro Carlos Wittmann, in memoriam, como um grande impulsionador do processo investigativo e instituinte do devir humano e da sociedade.

Wittmann ingressou na FURB em 1993 como professor visitante, tendo se efetivado como professor do quadro no ano de 1999, e em 2006 aposentou-se. O Professor Doutor Lauro Carlos Wittmann, além de teólogo, foi graduado em Filosofia (1961) pela Pontifícia Universidade Católica do Rio Grande do Sul (PUCRS), Mestre em Educação (1976) pelo Instituto de Estudos Avançados em Educação (IESAE) da Fundação Getúlio Vargas no Rio de Janeiro, e doutorado (1980) e Pós-doutorado em Educação (1989) pela Universidade de Londres.

$\mathrm{Na}$ sua larga trajetória profissional, ocupou diversos cargos e funções no campo educacional, como Presidente da Associação Nacional de Política e Administração da Educação (ANPAE); Coordenador do Grupo de Pesquisa de 


\section{Atos de Pesquisa em Educação - ISSN 1809-0354 \\ Blumenau, v. 12, n.2, p.601-621, mai./ago. 2017 \\ DOI: http://dx.doi.org/10.7867/1809-0354.2017v12n2p601-621}

Administração da Educação: políticas, planejamento, gestão e avaliação, vinculado ao CNPq; Assessor dos Conselhos Municipais de Educação de Santa Catarina. Atuou também em diversos órgãos, como a Coordenação de Aperfeiçoamento de Pessoal de Nível Superior (CAPES); Instituto Nacional de Estudos e Pesquisas (INEP); Sociedade Brasileira para o Progresso da Ciência (SBPC), entre outras atividades.

Atuou ainda como professor nas seguintes instituições: Instituto de Estudos Avançados em Educação da Fundação Getúlio Vargas (IESAE/FGV), Universidade Federal da Paraíba (UFPB), Universidade Federal de Santa Catarina (UFSC) e Universidade Regional de Blumenau (FURB). Além da docência nas disciplinas de Representações Sociais, Teoria e Prática de Pesquisa em Educação, Teoria e Prática Pedagógica, exerceu, entre 2000 e 2003, o cargo de coordenador do Programa de Pós-Graduação em Educação da FURB.

Considerando as diversas produções acadêmicas e as significativas inserções e contribuições no campo educacional, ressalta-se a relevância sócio histórica da sua vida profissional e do seu pensamento instigante, crítico e poético.

Diante do exposto, pretende-se, neste artigo, identificar as principais temáticas das investigações que emergiram no Grupo de Pesquisa EduPesquisa do Programa de Pós-Graduação em Educação, Mestrado em Educação da Universidade Regional de Blumenau. Para Wittmann (2006, p. 136), Grupo de Pesquisa é uma "instituição autopoiética de produção de conhecimento, de sociabilidade e de prazerosidade."

\section{METODOLOGIA}

Trata-se de um estudo de revisão, caracterizado como Estado da Arte (PICHETH, 2007; ROMANOWSKI; ENS, 2006), com o propósito de identificar as principais temáticas das pesquisas que emergiram durante o período de 1997 a 2006, sob a orientação do pesquisador Lauro Carlos Wittmann, no Grupo EduPesquisa: Educação, Estado e Sociedade do Programa de Pós-Graduação/ Mestrado em Educação da FURB. 


\section{Atos de Pesquisa em Educação - ISSN 1809-0354 \\ Blumenau, v. 12, n.2, p.601-621, mai./ago. 2017 \\ DOI: http://dx.doi.org/10.7867/1809-0354.2017v12n2p601-621}

Considera-se que os estudos de revisão, de acordo com Vosgerau e Romanowski (2014, p. 167), buscam reconhecer a temporalidade histórica e "indicar as tendências e procedimentos metodológicos utilizados na área". Optou-se pela abordagem qualitativa, considerando as interlocuções metodológicas do Estado da Arte (MOROSINI; FERNANDES, 2014) e a trajetória histórica desse percurso, elucidando a produção científica realizada. Assim, este trabalho busca realizar um balanço das produções, por linhas de pesquisa, nas quais foram classificadas as dissertações produzidas, levando em consideração a perspectiva teórico-histórica e as concepções dos sujeitos desse tempo. Nesse sentido, ressalta-se que:

A perspectiva teórico-histórica, a embocadura epistemológico-teórica e o compromisso sócio-político, neste contexto, funda-se na concepção de pessoa, de formação humana e de sociedade para refletirmos sobre a pesquisa, o ensino e a extensão na nossa prática acadêmica. (WITTMANN,2006, p. 123).

Primeiramente, foi realizado um levantamento dos resumos das 28 dissertações vinculadas a quatro linhas de pesquisa, a saber: a) Epistemologia e Processos Metodológicos, com três dissertações; b) Historicidade SócioInstitucional da Educação, com nove dissertações; c) Políticas e Administração da Educação, com 13 dissertações; d) Educação, Estado e Sociedade, com o total de três dissertações. Para representar melhor os dados deste levantamento, as pesquisas foram apresentadas em quadros, contendo as seguintes informações: linha de pesquisa; título; autor; e ano de defesa.

A partir deste mapeamento, iniciou-se o processo de leitura flutuante do corpus dos dados da pesquisa para evidenciar: (i) quais as principais temáticas abordadas, de acordo com as linhas de pesquisa; (ii) que perspectivas metodológicas predominaram; e (iii) quais as contribuições das pesquisas realizadas.

\section{BALANÇO DAS PRODUÇÕES CIENTÍFICAS}

Apresenta-se, a seguir, o mapeamento de todas as dissertações, por linhas de pesquisa, desenvolvidas no período de 1997 a 2006, orientadas pelo Professor Lauro Carlos Wittmann. Neste reconhecimento da historicidade das pesquisas, é 


\section{Atos de Pesquisa em Educação - ISSN 1809-0354 \\ Blumenau, v. 12, n.2, p.601-621, mai./ago. 2017 \\ DOI: http://dx.doi.org/10.7867/1809-0354.2017v12n2p601-621}

possível dar visibilidade aos sujeitos envolvidos na sua construção histórica, acadêmica, em seu processo de educador e formação humana. Para Wittmann (2006, p. 124), a formação humana é um processo de aprendência que confronta saberes de ultrapassagem de si mesmos, pois "é nas relações sociais que se forja a têmpera humana. É no atelier da conviviabilidade que se cria o artefato humano." Assim,

Construo-me educador, companheiro na produção de uma prática educativa, com consciência das suas limitações, mas, sobretudo, (re)conhecendo a indispensável e insubstituível nova contribuição histórica da educação para a emancipação humana. (WITTMANN,1993, p.7).

Para apresentação das pesquisas realizadas, destacam-se nesta seção: a) as principais temáticas investigadas, de acordo com as linhas de pesquisa; b) os objetivos do estudo; e c) as respectivas abordagens metodológicas utilizadas.

Quadro 1 - Linha de Pesquisa: Epistemologia e Processos Metodológicos

\begin{tabular}{|c|c|c|}
\hline TíTULO & AUTOR & $\begin{array}{c}\text { ANO } \\
\text { DEFESA }\end{array}$ \\
\hline $\begin{array}{c}\text { Saúde ocupacional: diagnóstico nas } \\
\text { grandes empresas de Brusque e } \\
\text { desafios para educação }\end{array}$ & Rosiléa Clara Werner & 1997 \\
\hline O magistério como trabalho da mulher & $\begin{array}{c}\text { Maria do Carmo Machado de } \\
\text { Souza }\end{array}$ & 1997 \\
\hline $\begin{array}{c}\text { Fundamentos da interação pedagógica } \\
\text { na dinâmica da prática escolar }\end{array}$ & Maria Selma Grosch & 1998 \\
\hline
\end{tabular}

Fonte: das autoras.

No processo de mapeamento foram encontrados os três primeiros trabalhos orientados por Wittmann no Programa de Pós-graduação/Mestrado em Educação, identificados nesse período na linha de pesquisa denominada Epistemologia e processos metodológicos.

A dissertação de Werner (1997) teve como objetivo analisar o cumprimento das leis referentes à saúde do trabalhador e os programas de educação para sua saúde, bem como a metodologia pedagógica utilizada nesses programas nas grandes empresas de Brusque, Santa Catarina. Como questão de pesquisa, 


\section{Atos de Pesquisa em Educação - ISSN 1809-0354 \\ Blumenau, v. 12, n.2, p.601-621, mai./ago. 2017 \\ DOI: http://dx.doi.org/10.7867/1809-0354.2017v12n2p601-621}

apresentou: qual a relação do poder público municipal com a saúde do trabalhador, bem como, a atuação dos sindicatos dos trabalhadores? Foram realizadas entrevistas com os responsáveis pela saúde do trabalhador das nove grandes empresas de Brusque, os líderes dos sindicatos das empresas envolvidas, trabalhadores e secretário da saúde do Município.

No trabalho de Souza (1997), buscou-se desvendar as tramas que envolvem a mulher/professora no momento da sua escolha profissional. A autora analisou entrevistas com professoras da rede Municipal de Ensino da cidade de Brusque, SC, que trabalhavam nos anos iniciais do Ensino Fundamental.

A pesquisa de Grosch (1998) visou investigar a interação social como fundamento da prática pedagógica. Procurou identificar os fatores que contribuem para o processo ensino aprendizagem, como ocorrem as aprendizagens significativas nas relações sociais e fundamentalmente, as condições de interação qualitativa, na prática da atividade docente. $\mathrm{Na}$ análise etnológica do cotidiano escolar foi possível observar aspectos significativos de interação social no espaço da sala de aula.

Quadro 2 - Linha de Pesquisa: Historicidade Sócio Institucional da Educação

\begin{tabular}{|c|c|c|}
\hline TíTULO & AUTOR & ANO DEFESA \\
\hline $\begin{array}{c}\text { Ensino Agrícola em SC: investigações acerca das } \\
\text { relações entre educação e trabalho }\end{array}$ & Luiz Alberto Ferreira & 1995 \\
\hline $\begin{array}{c}\text { Serviço Social: desafios em novos tempos } \\
\text { A formação do educador na emergente sociedade } \\
\text { do conhecimento }\end{array}$ & $\begin{array}{c}\text { Hélio Floriano dos } \\
\text { Santos }\end{array}$ & 1997 \\
\hline $\begin{array}{c}\text { A criança e o adolescente nas políticas e práticas } \\
\text { públicas de Blumenau: de marginal a sujeito }\end{array}$ & Marilúcia Mattedi & 2000 \\
\hline $\begin{array}{c}\text { Relações interpessoais no cotidiano escolar } \\
\text { Administração da Educação: função pedagógica da } \\
\text { administração da educação }\end{array}$ & $\begin{array}{c}\text { Marisa Jurema } \\
\text { de Macedo Ribas }\end{array}$ & 2000 \\
\hline $\begin{array}{c}\text { Teoria, prática e formação do fisioterapeuta: } \\
\text { situação e perspectivas }\end{array}$ & Élide Kurban & 2000 \\
\hline
\end{tabular}




\section{Atos de Pesquisa em Educação - ISSN 1809-0354 \\ Blumenau, v. 12, n.2, p.601-621, mai./ago. 2017 \\ DOI: http://dx.doi.org/10.7867/1809-0354.2017v12n2p601-621}

\begin{tabular}{|c|c|c|}
\hline $\begin{array}{c}\text { Interlocução qualificante do docente de matemática: } \\
\text { fatores de envolvimento }\end{array}$ & $\begin{array}{c}\text { Evandro Felin } \\
\text { Londero }\end{array}$ & 2000 \\
\hline $\begin{array}{c}\text { A organização do trabalho escolar: os tempos e } \\
\text { espaços de formação humana }\end{array}$ & $\begin{array}{c}\text { Marcia Regina Selpa } \\
\text { de Andrade }\end{array}$ & 2002 \\
\hline
\end{tabular}

Fonte: das autoras.

Na linha de pesquisa Historicidade Sócio Institucional da Educação, encontrase, no estudo de Ferreira (1995), a caracterização do Ensino Agrícola de Nível Médio em Santa Catarina. O autor verificou a relação entre teoria e prática nas disciplinas técnicas, a vinculação das Escolas Agrícolas com o setor produtivo, o currículo escolar, o nível de escolaridade ligado à profissionalização e a inserção de formandos na atividade produtiva. A pesquisa serviu-se de observações, relatos oficiais e registros inéditos coletados ao longo de 13 anos de atuação docente, incluindo sua participação no CONEA - Conselho Estadual do Ensino Agrícola.

Steuck (1997), em seu trabalho intitulado "Serviço Social: desafios em novos tempos" buscou refletir sobre as demandas profissionais colocadas na atual conjuntura política, econômica e social, que justificam sua ação perante a sociedade. Discutiu a origem da profissão em uma sociedade de classes e seu compromisso com a classe trabalhadora.

O trabalho de Santos (1997), "A formação do educador na emergente sociedade do conhecimento", buscou estabelecer quais as demandas da Sociedade do Conhecimento e quais as demandas que historicamente foram colocadas ao curso de Pedagogia da Universidade do Vale do Itajaí (UNIVALI). Analisou o curso de Pedagogia a partir das categorias: ethos e cultural do derrotismo; trabalhador/aluno e o ensino noturno; espaço e ciência; gênero; currículo; qualificação docente.

A investigação de Mattedi (1998) pretendeu desvelar o processo de construção da Lei do Estatuto da Criança e do Adolescente de Blumenau. Para desenvolver essa pesquisa, utilizou-se da análise de conteúdo, por ser uma técnica que possibilita $\mathrm{o}$ estudo das mensagens manifestadas e/ou latentes quantitativamente e/ou qualitativamente de um determinado conteúdo da comunicação utilizado como base. 


\section{Atos de Pesquisa em Educação - ISSN 1809-0354 \\ Blumenau, v. 12, n.2, p.601-621, mai./ago. 2017 DOI: http://dx.doi.org/10.7867/1809-0354.2017v12n2p601-621}

Para Ribas (2000), a pesquisa teve como objeto de estudo a natureza das relações existentes na escola. O objetivo foi explicitar as várias facetas das relações gestadas na corresponsabilidade e na participação, visando amenizar ou clarear as relações antipedagógicas calcadas no autoritarismo e na permissividade que interferem para uma escola participativa. Para isso, a metodologia utilizada foi um estudo de caso em um Colégio da Rede Estadual de Ensino na cidade de Jaraguá do Sul, Santa Catarina. O autor realizou uma leitura analítica dos dados levantados a partir de observação e entrevista para organizar uma lista com as características comportamentais encontradas, evidenciando suas diversidades.

João (2000) teve como objeto de estudo a função pedagógica da administração da educação. Sua função pedagógica foi explicitada com base na articulação entre os fundamentos teóricos (literatura) e experiências concretas, por meio de observações participativas na construção do Projeto Político Pedagógico, da prática administrativa e de sua relação com a prática pedagógica na escola.

Kurban (2000) desvelou os principais determinantes da Fisioterapia. Partiu da preocupação em construir o Projeto Pedagógico do curso de Fisioterapia da Universidade Regional de Blumenau, de forma que fizesse sentido no contexto atual e pelo real comprometimento com a saúde dos seres humanos.

A pesquisa de Londero (2000), intitulada "Interlocução qualificante do docente de matemática: fatores de envolvimento", teve como objetivo detectar os fatores que motivaram a (não) participação dos professores docentes de Matemática, da região do Médio Vale do Itajaí, em Santa Cataria, no projeto Redemat. Os dados foram obtidos por meio de entrevistas, questionário, seminários, congressos e debates.

A pesquisa de Andrade (2002) teve como objetivo identificar os determinantes da organização por Ciclos de Formação, trazendo as concepções que fundamentam essa organização do tempo e espaço escolar. Serviram como fonte de dados: a) leitura de diferentes propostas por ciclos implementadas no Brasil, fazendo uma análise documental; b) observação e registro das narrativas dos educadores/as, nos encontros pedagógicos; c) análise das experiências buscando elementos da proposta vivenciada. No desvelamento das características, foram utilizados os seguintes eixos: ressignificação dos tempos e espaços; a reestruturação e a diferença da escola em ciclos de formação e a seriada. 


\section{Atos de Pesquisa em Educação - ISSN 1809-0354 \\ Blumenau, v. 12, n.2, p.601-621, mai./ago. 2017 \\ DOI: http://dx.doi.org/10.7867/1809-0354.2017v12n2p601-621}

Quadro 3 - Linha de Pesquisa: Políticas e Administração da Educação - 2002

\begin{tabular}{|c|c|c|}
\hline TíTULO & AUTOR & ANO \\
DEFESA \\
\hline $\begin{array}{c}\text { Gestão da proposta educativa escolar: exigências e } \\
\text { perspectivas }\end{array}$ & Janete Adriano Küpper & 2002 \\
\hline $\begin{array}{c}\text { Educação Física e promoção humana } \\
\text { A orientação educacional na sociedade do } \\
\text { conhecimento }\end{array}$ & Joel Roberto Benghi & 2002 \\
\hline $\begin{array}{c}\text { O pai no olhar do professor: um estudo de } \\
\text { representação social }\end{array}$ & $\begin{array}{c}\text { Rosnelda Ponick } \\
\text { BuseloTheis }\end{array}$ & 2002 \\
\hline $\begin{array}{c}\text { A pesquisa/investigação como instrumento didático na } \\
\text { re)construção de conceitos geográficos básicos no } \\
\text { ensino fundamental }\end{array}$ & $\begin{array}{c}\text { Mariângela Leão da } \\
\text { Silva Antunes }\end{array}$ & 2002 \\
\hline $\begin{array}{c}\text { A formação do/a assistente social na sociedade } \\
\text { aprendente }\end{array}$ & $\begin{array}{c}\text { Dulce Teresinha Heinck } \\
\text { O lúdico na formação humana }\end{array}$ & 2002 \\
\hline $\begin{array}{c}\text { Política de organização do aprender escolar: lições de } \\
\text { processos alternativos }\end{array}$ & $\begin{array}{c}\text { Eliane Kormann } \\
\text { Tomazoni }\end{array}$ & 2002 \\
\hline
\end{tabular}

Fonte: das autoras.

Na linha de pesquisa Políticas e Administração da Educação, percebe-se um número expressivo de dissertações. Para melhor entendimento, apresentar-se-á essas dissertações em dois quadros. No Quadro 3, apresentam-se as pesquisas realizadas no ano de 2002 dos pesquisadores Küpper, Benghi, Theis, Ponick, Antunes e Tomazoni.

O estudo de Küpper (2002) explicou as características essenciais da escola na construção do seu Projeto Político Pedagógico (PPP), respondendo ao contexto sociocultural que define sua relevância. Confrontando a teoria das práticas de gestão com a prática desenvolvida na Rede Municipal de Ensino de Brusque/SC, buscou características exigidas para a gestão. Os dados foram coletados em quatro escolas da rede com ensino que possuíam uma proposta pedagógica relevante.

O estudo de Benghi (2002) teve origem no processo de reconstrução do Projeto Pedagógico de um curso de Educação Física. Objetivou explicitar o sentido, as tendências e características da Educação Física voltada para a saúde e qualidade de vida. O objeto foi explicitado no confronto entre a literatura, os 


\section{Atos de Pesquisa em Educação - ISSN 1809-0354 \\ Blumenau, v. 12, n.2, p.601-621, mai./ago. 2017 \\ DOI: http://dx.doi.org/10.7867/1809-0354.2017v12n2p601-621}

documentos do curso e prática concreta dos professores. Foram analisados documentos do curso, autores da área e realizado um confronto entre o que preconizam os teóricos e o que a prática revela.

A pesquisa de Theis (2002) desvelou o sentido e a (re)orientação da educação no novo contexto da sociedade do conhecimento. O objetivo foi contribuir para a ampliação da relevância histórica da Orientação Educacional na prática educativa escolar. A pesquisa tomou por base empírica os dados da realidade escolar da 4. ${ }^{\text {a }}$ Coordenadoria Regional de Educação.

Ponick (2002) confrontou a prática educativa do psicólogo escolar em especial com as dificuldades dos professores no dia a dia de sua atuação na escola. Nas dificuldades levantadas, destacou questões referentes à família. $\mathrm{O}$ autor definiu o real objeto de estudo: identificar elementos da Representação Social dos professores em relação aos pais. O levantamento de dados com relação ao pensar do professor sobre os pais foi ampliado por meio de entrevistas. Para complementar os dados levantados, elaborou-se um questionário para os professores.

Antunes (2002) estudou a pesquisa/investigação como instrumento pedagógico-didático na construção e elaboração de conceitos básicos do pensamento geográfico nas $5 .^{\text {as }}$ e $6 .{ }^{\text {as }}$ séries do ensino fundamental. Analisou uma experiência pedagógica que utiliza a pesquisa/investigação no processo de ensinoaprendizagem, fazendo uma comparação entre os resultados obtidos nesse processo e os resultados obtidos sem utilização intencional e sistemática da pesquisa/investigação.

Heinck (2002) apresentou a evolução e o processo atual da formação em Serviço Social. Analisou a pertinência e relevância dessa formação. Para essa análise, em uma época de aceleradas mudanças sociais, políticas, econômicas e culturais, buscou os novos determinantes da prática do/a assistente social na sociedade aprendente.

Silva (2002) teve como objeto o lúdico na formação humana. O objetivo foi explicitar o sentido do lúdico e suas dimensões e implicações na formação humana. A pesquisa foi desenvolvida de forma a responder três questões específicas: (1) como o conceito lúdico é tratado por diversos autores?; (2) qual a contribuição dos teóricos para a compreensão da relação entre a formação humana e o lúdico?; (3) 


\section{Atos de Pesquisa em Educação - ISSN 1809-0354 \\ Blumenau, v. 12, n.2, p.601-621, mai./ago. 2017 \\ DOI: http://dx.doi.org/10.7867/1809-0354.2017v12n2p601-621}

de que maneira a ludicidade pode contribuir para formar um sujeito mais livre e satisfeito? Utilizou o método bibliográfico e teórico.

Tomazoni (2002) estudou os elementos que determinam a aprendizagem de alunos repetentes em espaços alternativos de ensino e os elementos que travam 0 processo de aprender em espaços regulares. Fez um estudo teórico e empírico sobre as políticas de organização escolar, as denominadas classes de aceleração de estudos, no segmento de $5 .^{\circ}$ a $8^{\circ}$ ano do Ensino Fundamental, analisando a concepção, o currículo e a prática pedagógica de ambas as organizações. O estudo revelou que o fracasso escolar do aluno é fabricado pela própria escola da forma como esta se organiza. A pesquisa foi realizada em uma Escola da Rede Municipal de Ensino, no município de Brusque, SC, no segmento do Ensino Fundamental e nos espaços alternativos denominados como "classes de aceleração de estudos", que atendiam alunos repetentes.

Quadro 4 - Linha de Pesquisa: Políticas e Administração da Educação - 2003/2005

\begin{tabular}{|c|c|c|}
\hline TÍTULO & AUTOR & $\begin{array}{l}\text { ANO } \\
\text { DEFESA }\end{array}$ \\
\hline $\begin{array}{l}\text { Convergências entre dinâmica de grupo e prática } \\
\text { educativa na construção da autonomia }\end{array}$ & $\begin{array}{l}\text { Fábio Eduardo } \\
\text { Vellwock }\end{array}$ & 2003 \\
\hline $\begin{array}{l}\text { A boa escola sob o olhar do aluno: um estudo de } \\
\text { representações sociais }\end{array}$ & $\begin{array}{l}\text { Joceny Possas } \\
\text { Cascaes }\end{array}$ & 2003 \\
\hline $\begin{array}{c}\text { A inclusão sob o olhar do professor: um estudo de } \\
\text { representação social }\end{array}$ & $\begin{array}{l}\text { Rodrigo Marcellino de } \\
\text { França }\end{array}$ & 2003 \\
\hline $\begin{array}{l}\text { Formação médica: (des)construção do sentido da } \\
\text { profissão - a trajetória da representação social }\end{array}$ & $\begin{array}{l}\text { Tarcísio Lins } \\
\text { Arcoverde }\end{array}$ & 2004 \\
\hline $\begin{array}{l}\text { Participação na gestão escolar: envolvimento, } \\
\text { sentido e densidade }\end{array}$ & Maria José de Morais & 2005 \\
\hline
\end{tabular}

Fonte: das autoras.

No período de 2003 a 2005, representado no Quadro 4, a linha de pesquisa Políticas e Administração da Educação contou com os estudos de Vellwock, Cascaes, França, Arcoverde e Morais.

A pesquisa de Vellwock (2003) analisou as fases do desenvolvimento do grupo na construção da autonomia, visando detectar a contribuição pedagógica. Para tanto, relacionou a literatura especializada na área junto à psicologia do 


\section{Atos de Pesquisa em Educação - ISSN 1809-0354 \\ Blumenau, v. 12, n.2, p.601-621, mai./ago. 2017 \\ DOI: http://dx.doi.org/10.7867/1809-0354.2017v12n2p601-621}

desenvolvimento, a abordagem do desenvolvimento humano de José S. Fonseca Filho, com a construção da autonomia na prática docente. Com base nessa teoria, foi construído um referencial teórico sobre o desenvolvimento de grupo. Esse referencial foi produto/produtor de uma experiência concreta de evolução ou desenvolvimento de grupos em sala de aula.

Cascaes (2003), em sua pesquisa, desvelou a representação social dos alunos sobre 'boa escola'. Buscou concepções teóricas sobre a boa escola, a escola agradável e a prazerosidade na aprendizagem. O processo de desvelamento fundamentou-se na teoria e metodologia das Representações Sociais. Primeiro foram levantados dados junto aos alunos de uma escola sobre 'boa escola', por meio da livre associação de ideias e estabelecimento justificado de prioridades. Os dados foram analisados e, através de um processo de sucessivas convergências por significantes aglutinadores, foram enucleados determinantes da Representação Social.

Na pesquisa desenvolvida por França (2003), com o objetivo de desvelar os aspectos constituintes da representação social de inclusão pelos educadores, foi detectada a gestão pedagógica como $\circ$ elemento mais significativo para implementação do efetivo processo de inclusão de pessoas com necessidades especiais na escola regular. $O$ corpus se constituiu a partir de entrevistas e análises de desenhos - que representassem aspectos relacionados à inclusão dessas pessoas na escola comum - realizados com educadores do ensino fundamental.

O estudo de Arcoverde (2004) procurou mostrar, utilizando a Teoria das Representações Sociais, como ocorre a evolução da representação discente, durante o curso de Medicina, em relação à formação médica. Foram pesquisados alunos de todos os períodos do curso de Medicina da Universidade Regional de Blumenau - FURB, no ano de 2003.

Morais (2005) analisou a gestão democrática, por meio de uma pesquisa teórica empírica, com a finalidade de saber como se concretiza a participação na gestão escolar. Objetivou identificar os atores que dela participam, os objetos, as formas e níveis de participação dos mesmos em escolas de Ensino Fundamental da Rede Pública Estadual e Municipal em Blumenau, SC. Os dados foram coletados em observações, documentos, entrevistas, questionários e analisados quanto ao 


\section{Atos de Pesquisa em Educação - ISSN 1809-0354 \\ Blumenau, v. 12, n.2, p.601-621, mai./ago. 2017 \\ DOI: http://dx.doi.org/10.7867/1809-0354.2017v12n2p601-621}

envolvimento dos atores e sua mobilização, ao sentido e relevância, às formas e níveis de participação.

Quadro 5 - Linha de Pesquisa: Educação, Estado e Sociedade

\begin{tabular}{|c|c|c|}
\hline TíTULO & AUTOR & $\begin{array}{c}\text { ANO } \\
\text { DEFESA }\end{array}$ \\
\hline Encontro Pedagógico: espaço social de inclusão & 2006 \\
\hline A representação social do curso de fisioterapia: a visão do \\
formando & $\begin{array}{c}\text { Júlia Helena } \\
\text { Stein } \\
\text { Corrêa da } \\
\text { Cunha }\end{array}$ & 2006 \\
\hline A participação dos professores na escola constituinte em Lages, \\
1998: o escrito, o dito e o feito & $\begin{array}{c}\text { Ricardo Leone } \\
\text { Martins }\end{array}$ & 2006 \\
\hline
\end{tabular}

Fonte: das autoras.

A pesquisa de Raduenz (2006) descreve e analisa as formas de interação do meio escolar e explicita os indicadores de respeito às diferenças. Foi realizada em uma escola pública estadual de ensino fundamental que passa por uma experiência de atendimento integral de oito horas diárias. Os dados foram obtidos por meio da observação e descrição da forma como os professores lidam com as diferenças no contexto de sala de aula. Foram realizadas 15 observações. Nos procedimentos da pesquisa, analisou e explicitou as categorias utilizando a Hermenêutica. Os dados foram transformados em unidades de registro (80 cenas) que foram analisadas individualmente, buscando pontos de convergência entre elas que resultaram em unidades de significado. Essas unidades foram novamente organizadas e agrupadas por temas ou categorias de análise.

Cunha (2006) visou contribuir para a compreensão da relevância do curso de Fisioterapia na prática profissional. Explicitou os determinantes constitutivos da representação social dos formandos. Observou algumas tensões existentes nos formandos envolvidos com a parte prática. Fundamentou-se na Teoria das Representações Sociais e a coleta de dados foi feita por meio de questionário, buscando evocações livres.

O envolvimento dos professores na gestão democrática da educação foi o foco da pesquisa de Martins (2006), que analisou o processo da Escola Constituinte 
realizado em Lages, Santa Catarina, em 1998. A pesquisa procurou compreender se o envolvimento dos professores significou intervenção crítica ou mera submissão, a partir de uma metodologia que cruzou o escrito, o dito e o feito sobre a experiência analisada, categorizando a participação em efetiva, ativa, passiva e indiferente.

As investigações aqui socializadas, conforme mencionado na introdução deste artigo, foram realizadas sob a orientação do Professor Lauro Carlos Wittmann, que valorizava a pesquisa como fruto das experiências humanas. Por isso, fazer um balanço das produções científicas é reconhecer a historicidade das pesquisas, o valor do conhecimento que é vivência humana e afetiva, gerado do compartilhamento convivial (WITTMANN, 2006). Um grupo de pesquisa, segundo Wittmann (2006), é um espaço social privilegiado, como instituição autopoiética na produção e partilha do saber. 


\title{
Atos de Pesquisa em Educação - ISSN 1809-0354 \\ Blumenau, v. 12, n.2, p.601-621, mai./ago. 2017 \\ DOI: http://dx.doi.org/10.7867/1809-0354.2017v12n2p601-621
}

\section{CONTRIBUIÇÕES DAS PESQUISAS}

Este estudo se propôs a identificar as principais temáticas das investigações que emergiram no Grupo de Pesquisa EduPesquisa do Programa de PósGraduação em Educação/Mestrado em Educação da Universidade Regional de Blumenau e o legado destas produções.

As pesquisas analisadas caracterizam-se pelo seu papel crítico e fundante na construção do conhecimento, refletindo os processos desiguais e injustos na sociedade e os entraves das políticas públicas nos processos educativos. Segundo Wittmann (2006, p. 128), este é o papel da pesquisa:

\begin{abstract}
Assegurar que as políticas públicas tenham fundamento científico para poderem romper com os determinantes das desigualdades e da injustiça. Para superar o círculo vicioso da ignorância e da miséria as políticas não podem estar fundamentadas, apenas, na boa vontade e, muito menos, no oportunismo político. Os poucos recursos disponíveis demandam utilização racional e efetiva, fundada no conhecimento.
\end{abstract}

Nesse sentido, destaca-se que as 28 dissertações realizadas trazem temas pertinentes para o campo educacional, exercendo seu papel relevante nessa construção sociopolítica, fazendo emergir a autonomia e a cidadania dos sujeitos (WITTMANN, 2006).

As diferentes linhas de pesquisa: a) Epistemologia e Processos Metodológicos; b) Historicidade Sócio Institucional da Educação; c) Políticas e Administração da Educação; e d) Educação, Estado e Sociedade perpassam por diversas áreas do conhecimento. Tais pesquisas diferenciam-se entre si por abordarem processos educacionais e representações acerca de papéis sociais e profissionais que atuam nas diferentes modalidades sociais e educativas. Com objetivos distintos de pesquisa, desvelaram realidades e determinantes que as constituem, assim como possibilidades de transcendência.

Os estudos abordaram temas como gestão democrática; políticas públicas; inclusão; práticas educativas; currículo; emancipação humana; tempo e espaço escolar; formação humana, entre outros. Diante desses estudos, percebe-se uma predominância de aspectos da Educação Básica evidenciando elementos que constituem os processos de ensinar e aprender como relação professor e aluno, metodologias, processos de interação, didática, dinâmicas de grupo, formação 


\title{
Atos de Pesquisa em Educação - ISSN 1809-0354 \\ Blumenau, v. 12, n.2, p.601-621, mai./ago. 2017 \\ DOI: http://dx.doi.org/10.7867/1809-0354.2017v12n2p601-621
}

integral. Também se identificaram outros estudos voltados para a Educação Superior, mais precisamente para a formação de profissionais (Fisioterapia, Assistência Social, Serviço Social, Pedagogia e Medicina). Há algumas pesquisas com temas diferenciados, tratando da educação agrícola no Ensino Médio; da construção do Estatuto da Criança e do Adolescente; saúde do trabalhador em empresas; relação do sindicato na esfera do poder público.

No que se refere às abordagens metodológicas, todas as pesquisas se caracterizam como qualitativa. Observa-se uma tendência ao uso da teoria e da metodologia das Representações Sociais. Como instrumentos de geração de dados, as entrevistas predominam, seguidas de observações e questionários.

Nesse sentido, as pesquisas se constituíram desvelando processos educativos e de produção histórica que se estabelecem nas diferentes relações, o que, segundo Wittmann (2006, p. 126), caracteriza educação no sentido mais amplo:

\begin{abstract}
Como a educação, no sentido amplo, é o processo concreto de produção histórica da existência humana, todas as relações estabelecidas da pessoa com o mundo, com os outros e consigo mesma são parte do processo educativo. No processo histórico de forjamento das pessoas há intervenções educativas, que constituem a prática social educativa. Educação, no sentido estrito, é uma prática social que tem o objetivo de contribuir, direta e intencionalmente, no processo de construção histórica das pessoas. São intervenções educativas no forjamento histórico e concreto das pessoas.
\end{abstract}

As temáticas pesquisadas são relevantes e pertinentes ao tempo atual, mesmo que constituam estudos feitos há mais de uma década, visto que algumas problemáticas continuam presentes sendo ainda objeto de investigação.

Pode-se considerar, ainda, que quase todas as pesquisas remetem à nova organização da sociedade, denominada, por alguns, de sociedade do conhecimento (FONSECA, 2007) e, por outros, de sociedade aprendente (ASSMANN, 1996).

Reconhecer a historicidade das pesquisas nessa trajetória do professor Wittmann é considerar a relevante produção acadêmica e as significativas contribuições de seu legado na área educacional. As 28 temáticas pesquisadas trazem investigações articuladas, cenários educativos mobilizados em seus processos, políticas, espaços e sujeitos, reconhecendo a educação como princípio fundante da transformação social, e, ainda, a relevância sócio histórica da sua vida profissional e do seu pensamento instigante, crítico e poético. 
Atos de Pesquisa em Educação - ISSN 1809-0354

Blumenau, v. 12, n.2, p.601-621, mai./ago. 2017

DOI: http://dx.doi.org/10.7867/1809-0354.2017v12n2p601-621

\section{MARCIA REGINA SELPE HEINZLE}

Mestre em Educação pela Universidade Regional de Blumenau (FURB) e Doutora em Educação pela Universidade Estadual de Campinas (UNICAMP). Professora pesquisadora no Programa de Pós-Graduação em Educação da FURB. Líder do Grupo de Estudos e Pesquisas em Educação Superior GEPES/FURB. Professora Colaboradora do Mestrado em Saúde Coletiva. Coordenadora local do PARFOR/FURB.

\section{MARIA STELA BUSARELLO THEISS}

Mestre em Educação pela Universidade Regional de Blumenau (FURB). Atua na Gerência Regional de Educação de Blumenau. Integradora do Ensino Médio e Profissional.

\section{ELIANE KORMANN TOMAZONI}

Mestre em Educação pela Universidade Regional de Blumenau (FURB). Professora do Centro Universitário de Brusque (UNIFEBE). Assessora Pedagógica no Centro de Inovação Pedagógica de Desenvolvimento do Trabalho Docente/CIPD. Pesquisadora no Grupo de Estudos e Pesquisas do Ensino Superior GEPES/FURB.

\section{REFERÊNCIAS}

ANDRADE, M. R. S. A organização do trabalho escolar: os tempos e os espaços de formação humana. 2002. vii, 149 f., il. Dissertação (Mestrado) Universidade Regional de Blumenau, Centro de Ciências da Educação, Programa de Pós-Graduação em Educação, 2002.

ANTUNES, M. L. S. A pesquisa - investigação como prática pedagógica - 2002. 124 f. :il. Dissertação (Mestrado em Educação) - Programa de Pós-Graduação em Educação, Centro de Ciências da Educação, Universidade Regional de Blumenau, Blumenau, 2002.

ARCOVERDE, T. L. Formação médica: (des)construção do sentido da profissão: a trajetória da representação social. 2004. 128 f., il. Dissertação (Mestrado em Educação) - Programa de Pós-Graduação em Educação, Centro de Ciências da Educação, Universidade Regional de Blumenau, Blumenau, 2004.

ASSMANN, H. Metáforas novas para reencantar a Educação: epistemologia e didática. Piracicaba: Editora Unimep, 1996. 
Atos de Pesquisa em Educação - ISSN 1809-0354

Blumenau, v. 12, n.2, p.601-621, mai./ago. 2017

DOI: http://dx.doi.org/10.7867/1809-0354.2017v12n2p601-621

BENGHI, J. R. Educação física e promoção humana - 2002. - ix, 84 f.:il.

Dissertação (Mestrado em Educação) - Programa de Pós-Graduação em Educação, Centro de Ciências da Educação, Universidade Regional de Blumenau, Blumenau, 2002.

CASCAES, J. P. A escola sob o olhar do aluno: um estudo de representações sociais. 2004. 102 f, il. Dissertação (Mestrado em Educação) - Programa de PósGraduação em Educação, Centro de Ciências da Educação, Universidade Regional de Blumenau, Blumenau, 2004.

CUNHA, J. H. S. C. A representação social do curso de Fisioterapia: a visão do formando - 2006. - 96 f.:il. Dissertação (Mestrado em Educação) - Programa de Pós-Graduação em Educação, Centro de Ciências da Educação, Universidade Regional de Blumenau, Blumenau, 2006.

FERREIRA, L. A. Ensino agrícola em Santa Catarina: investigações acerca das relações entre educação e trabalho. 1995.viii, 159 f, il. Dissertação (Mestrado em Educação) - Programa de Pós-Graduação em Educação, Centro de Ciências da Educação, Universidade Regional de Blumenau, Blumenau, 1995.

FONSECA, M. O Banco Mundial e a Educação: reflexão sobre o caso brasileiro. In: GENTILI, Pablo (org) Pedagogia da Exclusão: criticas ao neoliberalismo em educação. Petrópolis: vozes, 2007.

FRANÇA, R. M. A inclusão sob o olhar do professor: um estudo de representação. 2003.80 f, il. Dissertação (Mestrado em Educação) - Programa de Pós-Graduação em Educação, Centro de Ciências da Educação, Universidade Regional de Blumenau, Blumenau, 2003.

GROSCH, M. S. Fundamentos da interação pedagógica na dinâmica da prática escolar. 1998. xi, 91 f. Dissertação (Mestrado em Educação) - Dissertação (Mestrado em Educação) - Programa de Pós-Graduação em Educação, Centro de Ciências da Educação, Universidade Regional de Blumenau, Blumenau, 1998.

HEINECK, D. T. Formação do(a) assistente social na sociedade aprendente. 2002.viii,124 f. Dissertação (Mestrado em Educação) - Programa de Pós-graduação em Educação, Centro de Ciências da Educação, Universidade Regional de Blumenau, Blumenau, 2002.

JOÃO, L. Administração da educação: função pedagógica da administração da educação - 2000. - 99 f. Dissertação (Mestrado em Educação) - Programa de PósGraduação em Educação, Centro de Ciências da Educação, Universidade Regional de Blumenau, Blumenau, 2000.

KURBAN, É. Teoria, prática e formação do fisioterapeuta: situação e perspectivas - 2000. - vii, 91 f.: il. Dissertação (Mestrado em Educação) - Programa de PósGraduação em Educação, Centro de Ciências da Educação, Universidade Regional de Blumenau, Blumenau, 2000. 
Atos de Pesquisa em Educação - ISSN 1809-0354

Blumenau, v. 12, n.2, p.601-621, mai./ago. 2017

DOI: http://dx.doi.org/10.7867/1809-0354.2017v12n2p601-621

KÜPPER, J. A. Gestão da proposta educativa escolar: exigências e perspectivas 2002. - vii, 83 f. Dissertação (Mestrado em Educação) - Programa de PósGraduação em Educação, Centro de Ciências da Educação, Universidade Regional de Blumenau, Blumenau, 2002.

LONDERO, E. F. Interlocução qualificante do docente de matemática: fatores de envolvimento- 2000. - 110 f. Dissertação (Mestrado em Educação) - Programa de Pós-Graduação em Educação, Centro de Ciências da Educação, Universidade Regional de Blumenau, Blumenau, 2000.

MARTINS, R.L. A participação dos professores na escola constituinte em Lages, 1998: o escrito, o dito e o feito. 2006.127 f. Dissertação (Mestrado em Educação) - Programa de Pós-Graduação em Educação, Centro de Ciências da Educação, Universidade Regional de Blumenau, Blumenau, 2006.

MATTEDI, M. A criança e o adolescente nas políticas e práticas públicas de Blumenau: de marginal a sujeito. 1998. 164 f, il. Dissertação (Mestrado) - Programa de Pós-Graduação em Educação, Centro de Ciências da Educação, Universidade Regional de Blumenau, Blumenau, 1998.

MORAIS, M.J. Participação na gestão escolar: envolvimento, sentido e densidade. 2005.134 f, il. Dissertação (Mestrado em Educação) - Programa de Pós-Graduação em Educação, Centro de Ciências da Educação, Universidade Regional de Blumenau, Blumenau, 2005.

MOROSINI, M. C. FERNANDES, C. M. B.. Estado do Conhecimento: conceitos, finalidades e interlocuções. Educação Por Escrito, v. 5, n. 2, p. 154-164, 2014.

PICHETH, F. M. PeArte: um ambiente colaborativo para a formação do pesquisador que atua no ensino superior por meio da participação em pesquisas do tipo estado da arte. 2007. 139 f. Dissertação (Mestrado em Educação) - Pontifícia Universidade Católica do Paraná, Curitiba, 2007.

PONICK, R. O pai no olhar do professor: um estudo de representações sociais 2002. - 66 f.: il. Dissertação (Mestrado em Educação) - Programa de Pós-Graduação em Educação, Centro de Ciências da Educação, Universidade Regional de Blumenau, Blumenau, 2002.

RADUENZ, M. Encontro pedagógico: espaço social de inclusão. $2006.114 \mathrm{f}$. Dissertação (Mestrado em Educação) - Programa de Pós-Graduação em Educação, Centro de Ciências da Educação, Universidade Regional de Blumenau, Blumenau, 2006.

RIBAS, M.J.S.B.M. Relações interpessoais no cotidiano escolar - 2000. - xi, 110 f. Dissertação (Mestrado em Educação) - Programa de Pós-Graduação em Educação, Centro de Ciências da Educação, Universidade Regional de Blumenau, Blumenau, 2000. 
Atos de Pesquisa em Educação - ISSN 1809-0354

Blumenau, v. 12, n.2, p.601-621, mai./ago. 2017

DOI: http://dx.doi.org/10.7867/1809-0354.2017v12n2p601-621

ROMANOWSKI, J.P.; ENS, R.T. As pesquisas denominadas do tipo "estado da arte" em educação. Revista Diálogo Educacional, v. 6, n. 19, p. 37-50, 2006.

SANTOS, H.F. A formação do educador na emergente sociedade do conhecimento - 1997. - viii, 133 f. Dissertação (Mestrado em Educação) - Programa de Pós-Graduação em Educação, Centro de Ciências da Educação, Universidade Regional de Blumenau, Blumenau, 1997.

SILVA, M. K. O lúdico na formação humana - 2002. - 70 f.Dissertação (Mestrado em Educação) - Programa de Pós-Graduação em Educação, Centro de Ciências da Educação, Universidade Regional de Blumenau, Blumenau, 2002.

SOUZA, M. C. M. O magistério como trabalho da mulher - 1997. - 129 f. :il. Dissertação (Mestrado em Educação) - Programa de Pós-Graduação em Educação, Centro de Ciências da Educação, Universidade Regional de Blumenau, Blumenau, 1997.

STEUCK, A.M. Serviço social: desafios em novos tempos. 1997.vii, $53 \mathrm{f}$.

Dissertação (Mestrado) - Universidade Regional de Blumenau, Blumenau, 1997.

THEIS, M. S.B. A orientação educacional na sociedade do conhecimento 2002. - xiii, 100 f. Dissertação (Mestrado) - Universidade Regional de Blumenau, Centro de Ciências da Educação, Programa de Pós-Graduação em Educação, 2002.

TOMAZONI, E. K. Política de organização do aprender escolar: lições de processos alternativos. 2002.112 f, il. Dissertação (Mestrado em Educação) Programa de Pós-Graduação em Educação, Centro de Ciências da Educação, Universidade Regional de Blumenau, Blumenau, 2002.

VELLWOCK, F.E. Convergências entre dinâmica de grupo e prática educativa naconstrução da autonomia- 2003. - 175 f.: il. Dissertação (Mestrado em Educação) - Programa de Pós-Graduação em Educação, Centro de Ciências da Educação, Universidade Regional de Blumenau, Blumenau, 2002.

VOSGERAU, D. S. A.R.; ROMANOWSKI, J. P. Estudos de revisão: implicações conceituais e metodológicas. Revista Diálogo Educacional, Curitiba, v. 14, n. 41, p. 165-189, jan./abr. 2014.

WERNER, R.C. Saúde ocupacional: diagnóstico nas grandes empresas de Brusque e desafios para educação - 1997. - vi, 111 f. :il. Dissertação (Mestrado em Educação). Programa de Pós-Graduação em Educação, Centro de Ciências da Educação, Universidade Regional de Blumenau, Blumenau, 1997.

WITTMANN, L. C.. A relevância histórica da pós-graduação em educação na construção da qualidade social. Atos de Pesquisa em Educação, v. 1, n. 2, p. 120 139, 2006. 
Atos de Pesquisa em Educação - ISSN 1809-0354

Blumenau, v. 12, n.2, p.601-621, mai./ago. 2017

DOI: http://dx.doi.org/10.7867/1809-0354.2017v12n2p601-621

WITTMANN, L. C. Chão de escola: a (cons)ciência do cotidiano educativo: parábolas. Florianópolis : Ed. do Autor, 1993. 